\title{
Synthesis of Polyethers Containing Triazole Units in the Backbone by Click Chemistry in a Tricomponent Reaction
}

\author{
Moslem Mansour Lakouraj, Vahid Hasantabar, and Nazanin Bagheri \\ Department of Polymer Chemistry, Faculty of Chemistry, University of Mazandaran, Babolsar 47416, Iran \\ Correspondence should be addressed to Moslem Mansour Lakouraj; lakouraj@umz.ac.ir
}

Received 25 March 2013; Revised 23 July 2013; Accepted 13 August 2013

Academic Editor: Cyrille Boyer

Copyright (c) 2013 Moslem Mansour Lakouraj et al. This is an open access article distributed under the Creative Commons Attribution License, which permits unrestricted use, distribution, and reproduction in any medium, provided the original work is properly cited.

\begin{abstract}
A series of linear aromatic polyethers containing triazole units were synthesized via the direct click reaction of dibromide and bisethynyl compounds in the presence of sodium azide as one pot reaction. The structures of polymers were approved by using IR and ${ }^{1} \mathrm{H}$ NMR techniques. The solubility experiments showed that polymers have good solubility in polar aprotic solvents such as DMSO, DMF, and NMP at higher temperatures. Thermal stability of the polymers was measured using thermogravimetric analysis (TGA) and differential scanning calorimetry (DSC) which indicated that they possessed good thermal stability $\left(T_{50}\right.$ up to $\left.558^{\circ} \mathrm{C}\right)$ and high $T_{g}\left(191.7-260^{\circ} \mathrm{C}\right)$ under $\mathrm{N}_{2}$ atmosphere. All the polymers were amorphous according to the DSC and X-ray diffraction. These polymers exhibited strong UV-vis absorption maxima near to $400 \mathrm{~nm}$ and up to $500 \mathrm{~nm}$ in DMSO solution.
\end{abstract}

\section{Introduction}

Poly(arylene ether)s (PAEs) are known as an important class of the high-performance polymeric materials which consist of aromatic rings and ether linkages [1]. So far, one of the most common and effective methods for the formation of aromatic ether linkages in polyether synthesis was nucleophilic aromatic substitution $\left(S_{N} A r\right)$ reaction. Different poly(aryl ether)s including poly(ether sulfone)s, poly(ether ketone)s, and poly(ether imide)s have been prepared using the $S_{N} A r$ reaction and commercialized [2]. However, this method suffers from some serious limitations such as high temperature and harsh conditions. In addition, only appropriate monomers having electron-withdrawing groups at the ortho position to the leaving group could be polymerized.

Recent innovations in synthetic methodology have improved polymer synthesis, enabling the custom design of a large variety of macromolecular architectures under incorporation of desired functional units $[3,4]$. To find an outstanding polymerization reaction, polymer chemists and biotechnologists have increasingly turned towards advanced synthetic organic concepts. In this respect, the most interesting one is click chemistry well documented in the past decade.
The applications of click reactions are wide in scope. The click reactions give excellent yields and generate inoffensive by-products that can be removed by convenient methods. The required process characteristics include simple reaction conditions, readily available reactants, solvent free reactions or using a solvent that is benign or easily removed, and simple product isolation [5].

To date, the most popular reaction that satisfied these features is the 1,3-dipolar cycloaddition, also known as Huisgen cycloaddition, between an azide and a terminal alkyne which affords the triazole moiety [6]. The applicability of this reaction is very high, since alkyne and azide components can be incorporated into a wide range of substituents [7]. Unfortunately, this reaction suffers from a lack of selectivity yielding a mixture of the 1,4- and the 1,5-regioisomers. Furthermore, this transformation requires heating and long reaction times to go to completion, and the mixtures of regioisomers are at times laborious to separate using classical chromatographic procedures [7]. Recently, it has been reported that copper(I) salts accelerate the reaction rate enormously. Surprisingly, the copper catalyst produces only the 1,4-regioisomer at room temperature in moderate heating $[8,9]$. 


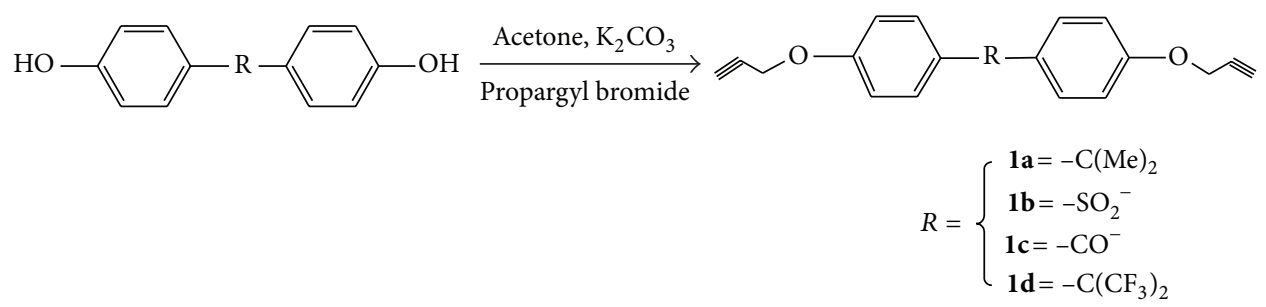

SCHEme 1: Synthesis of bis propargyl ethers.

Although, the applications of click reaction in materials science are especially interesting, most of them were focused on the preparation of dendronized polymers [10,11] and conjugated polymers [12] or limited to incorporation of 1,2,3triazole rings into polymers by graft polymerization [13-15]. According to our literature survey, it is found that the 1,2,3triazole ring was rarely incorporated into the backbone of linear poly(arylene ether)s [16-19].

In this paper, we wish to describe the synthesis and characterization of a novel class of linear aromatic and aliphatic polyethers such as poly(ether ketone)s, poly(ether sulfone)s, and fluorinated poly ether containing triazole units in the backbone via the in situ click reaction of bisethynyl and dibromide compounds in the presence of sodium azide as a tricomponents reaction.

\section{Materials and Methods}

Acetone was dried over $\mathrm{CaH}_{2}$ and distillated before use. Other reagents or materials were used as received. The chemicals used in this experiment were purchased from Merck (Germany).

2.1. Characterization. Melting points were measured by an Electrothermal 9100 apparatus. ${ }^{1} \mathrm{H}$ NMR spectra were recorded on a Bruker DRX-400. IR spectra were recorded on a Perkin Elmer FT-IR- 1710 spectrophotometer. Thermogravimetric analysis (TGA) and differential scanning calorimetry (DSC) were recorded on a thermal science PLSTA 1500 system under nitrogen atmosphere at a heating rate of $10^{\circ} \mathrm{C} \mathrm{min}{ }^{-1}$. Inherent viscosity at a concentration of $0.5 \mathrm{~g} / \mathrm{dL}$ was measured with an Ubbelohde suspended-level viscometer at $25^{\circ} \mathrm{C}$ in DMSO solution. X-ray diffraction (XRD) patterns were obtained at room temperature on a Rigaku D/Max-2550 powder diffractometer with a scanning speed of $5^{\circ} \mathrm{min}^{-1}$, and the patterns were recorded in the $2 \theta$ range of $5-50^{\circ}$. Relative molecular weights and distributions were measured by gel permeation chromatography (GPC) system equipped with a Waters 1515 Isocratic HPLC pump, a Waters 2414 refractive index (RI) detector, a Waters 2487 dual wavelength $\lambda$ absorbance detector, and a set of Waters Styragel columns (HR3, HR4, and HR5, $7.8 \mathrm{~mm} \times 300 \mathrm{~mm}$ ). GPC measurements were carried out at $35^{\circ} \mathrm{C}$ using $\mathrm{DMF}$ as eluent at a flow rate of $1.0 \mathrm{~mL} / \mathrm{min}$. Ultraviolet-visible spectra were recorded on a Cecil 5503 (Cecil Instruments,
Cambridge, UK) spectrophotometers using a dilute polymer solution $(0.20 \mathrm{~g} / \mathrm{dL})$ in DMSO.

2.2. Synthesis of Bis Propargyl Ether of Bisphenol. Bisphenol $(0.05 \mathrm{~mol})$, potassium carbonate $(0.15 \mathrm{~mol})$, dry acetone $(50 \mathrm{~mL})$, and propargyl bromide $(0.125 \mathrm{~mol})$ were mixed in a round bottom flask equipped with a condenser and a heater stirrer. Then the mixture was kept at $80^{\circ} \mathrm{C}$ overnight. On completion of the reaction, the solvent was evaporated and the product was washed with $5 \% \mathrm{~K}_{2} \mathrm{CO}_{3}$ aq. and deionized water several times. The crude product was purified by column chromatography on silica gel using $n$-hexane/ethyl acetate $(4: 1)$ as eluent to give $\mathbf{1 a}-\mathbf{d}$. Then, it was recrystallized from ethanol twice to obtain crystalline monomers. Synthesis of bis propargyl ethers of bisphenols is shown in Scheme 1.

1a: Yield: $90 \%$. m.p. $80-82^{\circ} \mathrm{C}$ [20].

lb: Yield: $85 \%$. m.p. $180-182^{\circ} \mathrm{C}[20]$.

1c: Yield: $88 \%$. m.p. $89-90^{\circ} \mathrm{C}$ [20].

1d: Yield: 89\%. Oil; IR ( $\left.\mathrm{KBr}, \mathrm{cm}^{-1}\right): 3299(\equiv \mathrm{CH}), 2127$ $(\mathrm{C} \equiv \mathrm{C}) ; 1247(\mathrm{Ar}-\mathrm{O}) ; 1189\left(\mathrm{O}-\mathrm{CH}_{2}\right) ; 827\left(-\mathrm{CF}_{3}\right) ;{ }^{1} \mathrm{H} \mathrm{NMR}$ $\left(400 \mathrm{MHz} \mathrm{CDCl}_{3}\right) \delta: 2.59(\mathrm{tr}, J=2.4 \mathrm{~Hz}, 2 \mathrm{H}, \equiv \mathrm{CH}), 4.79$ $\left(\mathrm{d}, J=2.4 \mathrm{~Hz}, 4 \mathrm{H},-\mathrm{CH}_{2}\right), 7.06(\mathrm{~d}, J=9.2 \mathrm{~Hz}, 4 \mathrm{H},-\mathrm{O}-\mathrm{Ar}-$ $\mathrm{H}), 7.82(\mathrm{~d}, J=9.2 \mathrm{~Hz}, 4 \mathrm{H},-\mathrm{C}-\mathrm{Ar}-\mathrm{H}) ;{ }^{13} \mathrm{C} \mathrm{NMR}(100 \mathrm{MHz}$, $\mathrm{CDCl}_{3}$ ) $\delta: 55.8,66.3,76.1,77.8,114.3,131.3,132.1,160.7,194.3$. $\mathrm{MS} m / z$ (relative intensity) 412 .

2.3. Synthesis of Polymer $\mathbf{1 a}-\boldsymbol{d}$ and $2 \boldsymbol{a}-\boldsymbol{d}$ from Bis Propargyl Aryl Ethers and Dibromides. In a $25 \mathrm{~mL}$ flask, to a solution of bisethynyl compounds $(0.50 \mathrm{mmol})$, dibromide $(146 \mathrm{mg}$, $0.50 \mathrm{mmol})$ and sodium azide $(71.5 \mathrm{mg}, 1.1 \mathrm{mmol})$ in $\mathrm{DMF}$ $(10 \mathrm{~mL})$, was added a suspension of $\mathrm{CuCl}(9.85 \mathrm{mg}, 20 \mathrm{~mol} \%)$ in $\mathrm{H}_{2} \mathrm{O}(2 \mathrm{~mL})$ in dropwise. Then $\mathrm{NEt}_{3}$ was added gradually until color of mixture changes from brown to light green. The reaction mixture was stirred at room temperature for $24 \mathrm{~h}$. The reaction mixture was diluted by water $(20 \mathrm{~mL})$ and then concentrated ammonia $(5 \mathrm{~mL})$ was added and stirred for another $1 \mathrm{~h}$. The mixture was filtered and the resulting solid material was washed with $\mathrm{H}_{2} \mathrm{O}$, methanol, and THF. Finally, the obtained polymer was further purified using continuous extraction by soxhlet in THF.

P1a: $90 \%$ yield. IR (KBr, $\left.\mathrm{cm}^{-1}\right)$ : 3180, 3085, 2929, 1650, 1604, 1508, 1430, 1307, 1226, 1180, 1018, 829, 688. ${ }^{1} \mathrm{H}$ NMR (DMSO-d6, $400 \mathrm{MHz}, \mathrm{ppm}) \delta: 8.11$ (s, 2H, CH of triazole ring), 7.63 (br, $4 \mathrm{H}$, phenyl), 7.11 (br, $4 \mathrm{H}$, phenyl), 6.91 (br, $4 \mathrm{H}$, phenyl), 4.71 (br, $4 \mathrm{H}, \mathrm{CH}_{2}-\mathrm{O}$ ), 4.25 (br, $4 \mathrm{H}, \mathrm{CH}_{2}-\mathrm{N}$ ), 1.68 (s, 


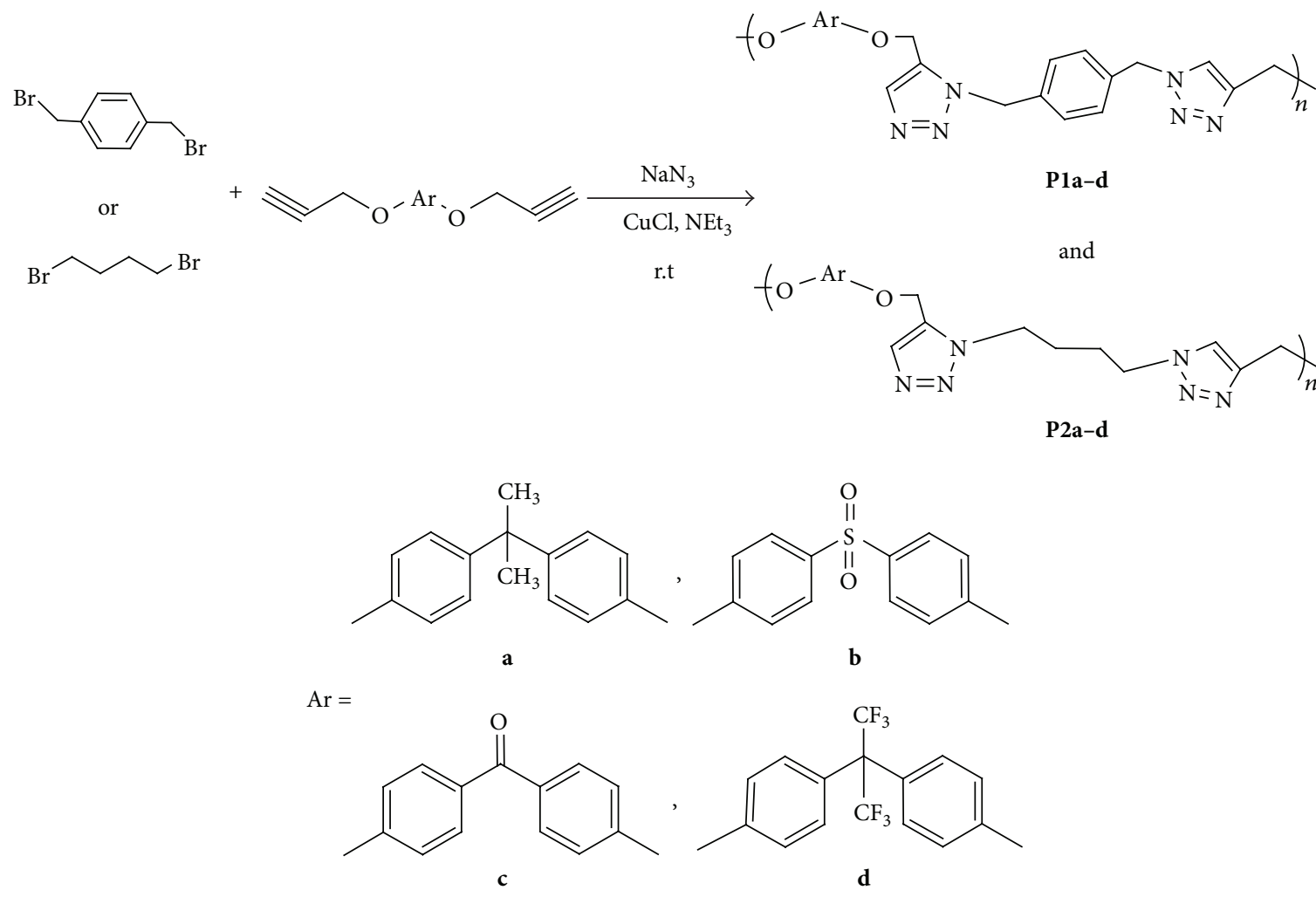

Scheme 2: Synthesis of poly(triazole ether)s.

$\left.6 \mathrm{H}, \mathrm{CH}_{3}\right)$. Anal. Calc. for $\left(\mathrm{C}_{29} \mathrm{H}_{28} \mathrm{~N}_{6} \mathrm{O}_{2}\right)_{n}$ : $\mathrm{C} 70.73, \mathrm{H} 5.69, \mathrm{~N}$ 17.07. Found: C 71.25, H 5.56, N 17.81\%.

P1b: $93 \%$ yield. IR $\left(\mathrm{KBr}, \mathrm{cm}^{-1}\right)$ : 3140, 3058, 2920, 1592, 1494, 1459, 1294, 1253, 1177, 1149, 1106, 1050, 998. ${ }^{1} \mathrm{H}$ NMR (DMSO-d6, $400 \mathrm{MHz}, \mathrm{ppm}) \delta: 8.19$ (s, 2H, CH of triazole ring), 7.83 (br, $4 \mathrm{H}$, phenyl), 7.51 (br, $4 \mathrm{H}$, phenyl), 6.95 (br, $4 \mathrm{H}$, phenyl), 4.83 (br, $4 \mathrm{H}, \mathrm{CH}_{2}-\mathrm{O}$ ), $4.05\left(\mathrm{br}, 4 \mathrm{H}, \mathrm{CH}_{2}-\mathrm{N}\right.$ ). Anal. Calc. for $\left(\mathrm{C}_{26} \mathrm{H}_{22} \mathrm{~N}_{6} \mathrm{O}_{4} \mathrm{~S}\right)_{n}$ : C 60.7, H 4.28, N 16.34. Found: C 61.23, H 5.1, N 16.93\%.

Plc: $89 \%$ yield. IR $\left(\mathrm{KBr}, \mathrm{cm}^{-1}\right)$ : $3255,3056,2948,1644$, 1598, 1508, 1455, 1423, 1311, 1247, 1166, 998, 927. ${ }^{1} \mathrm{H}$ NMR (DMSO-d6, $400 \mathrm{MHz}, \mathrm{ppm}) \delta: 8.01(\mathrm{~s}, 2 \mathrm{H}, \mathrm{CH}$ of triazole ring), 7.52 (br, $4 \mathrm{H}$, phenyl), 7.21 (br, $4 \mathrm{H}$, phenyl), 7.01 (br, $4 \mathrm{H}$, phenyl), $4.64\left(\mathrm{br}, 4 \mathrm{H}, \mathrm{CH}_{2}-\mathrm{O}\right), 4.44\left(\mathrm{br}, 4 \mathrm{H}, \mathrm{CH}_{2}-\mathrm{N}\right)$. Anal. Calc. for $\left(\mathrm{C}_{27} \mathrm{H}_{22} \mathrm{~N}_{6} \mathrm{O}_{3}\right)_{n} \mathrm{C}$ 67.78, $\mathrm{H}$ 4.6, N 17.57. Found: C 68.34, H 4.86, N 18.01\%.

P1d: $83 \%$ yield. IR $\left(\mathrm{KBr}, \mathrm{cm}^{-1}\right)$ : 3139, 3045, 2958, 2875, $1614,1515,1461,1427,1249,1170,1051,962,825 .{ }^{1} \mathrm{H}$ NMR (DMSO-d6, $400 \mathrm{MHz}, \mathrm{ppm}) \delta: 8.16(\mathrm{~s}, 2 \mathrm{H}, \mathrm{CH}$ of triazole ring), 7.43 (br, $4 \mathrm{H}$, phenyl), 7.25 (br, $4 \mathrm{H}$, phenyl), 7.08 (br, $4 \mathrm{H}$, phenyl), 4.75 (br, $4 \mathrm{H}, \mathrm{CH}_{2}-\mathrm{O}$ ), $4.25\left(\mathrm{br}, 4 \mathrm{H}, \mathrm{CH}_{2}-\mathrm{N}\right)$. Anal. Calc. for $\left(\mathrm{C}_{29} \mathrm{H}_{22} \mathrm{~N}_{6} \mathrm{O}_{2} \mathrm{~F}_{6}\right)_{n} \mathrm{C} 556.49, \mathrm{H} 3.57, \mathrm{~N}$ 13.63. Found: $\mathrm{C} 55.63, \mathrm{H} 4.03, \mathrm{~N} 14.05 \%$.

P2a: $91 \%$ yield. IR $\left(\mathrm{KBr}, \mathrm{cm}^{-1}\right): 3180,3042,2962,1606$, $1508,1459,1363,1297,1242,1182,1011,830 .{ }^{1} \mathrm{H}$ NMR (DMSOd6, $400 \mathrm{MHz}, \mathrm{ppm}) \delta: 8.31$ (s, 2H, CH of triazole ring), 7.78 (br, $4 \mathrm{H}$, phenyl), 7.08 (br, $4 \mathrm{H}$, phenyl), 5.15 (br, $4 \mathrm{H}, \mathrm{CH}_{2}-\mathrm{O}$ ),

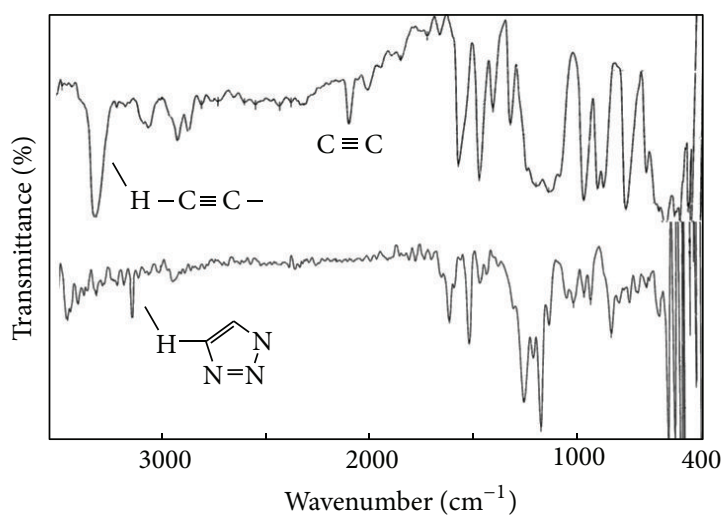

Figure 1: IR of 1d (up) and P2d (down) using the KBr tablets.

4.16 (br, $4 \mathrm{H}, \mathrm{CH}_{2}-\mathrm{N}$ ), 1.72 (s, 6H, $\mathrm{CH}_{3}$ ), 1.54 (br, $4 \mathrm{H}, \mathrm{CH}_{2}-$ $\left.\mathrm{CH}_{2}\right)$. Anal. Calc. for $\left(\mathrm{C}_{25} \mathrm{H}_{28} \mathrm{~N}_{6} \mathrm{O}_{2}\right)_{n} \mathrm{C}$ 67.56, H 6.3, N 18.91. Found: C 68.22, H 6.43, N 19.01\%.

P2b: $90 \%$ yield. IR $\left(\mathrm{KBr}, \mathrm{cm}^{-1}\right)$ : 3125, 3051, 2960, 1602, 1494, 1457, 1295, 1248, 1180, 1138, 1106, 1050, 998. ${ }^{1} \mathrm{H}$ NMR (DMSO-d6, $400 \mathrm{MHz}, \mathrm{ppm}) \delta: 8.21(\mathrm{~s}, 2 \mathrm{H}, \mathrm{CH}$ of triazole ring), 7.82 (br, $4 \mathrm{H}$, phenyl), 7.18 (br, $4 \mathrm{H}$, phenyl), $5.20(\mathrm{br}$, $\left.4 \mathrm{H}, \mathrm{CH}_{2}-\mathrm{O}\right), 4.36\left(\mathrm{br}, 4 \mathrm{H}, \mathrm{CH}_{2}-\mathrm{N}\right), 1.74\left(\mathrm{br}, 4 \mathrm{H}, \mathrm{CH}_{2}-\mathrm{CH}_{2}\right.$ ). Anal. Calc. for $\left(\mathrm{C}_{22} \mathrm{H}_{22} \mathrm{~N}_{6} \mathrm{O}_{4} \mathrm{~S}\right)_{n} \mathrm{C} 56.65, \mathrm{H}$ 4.72, N 18.02. Found: C 57.71, H 4.85, N 18.51\%. 

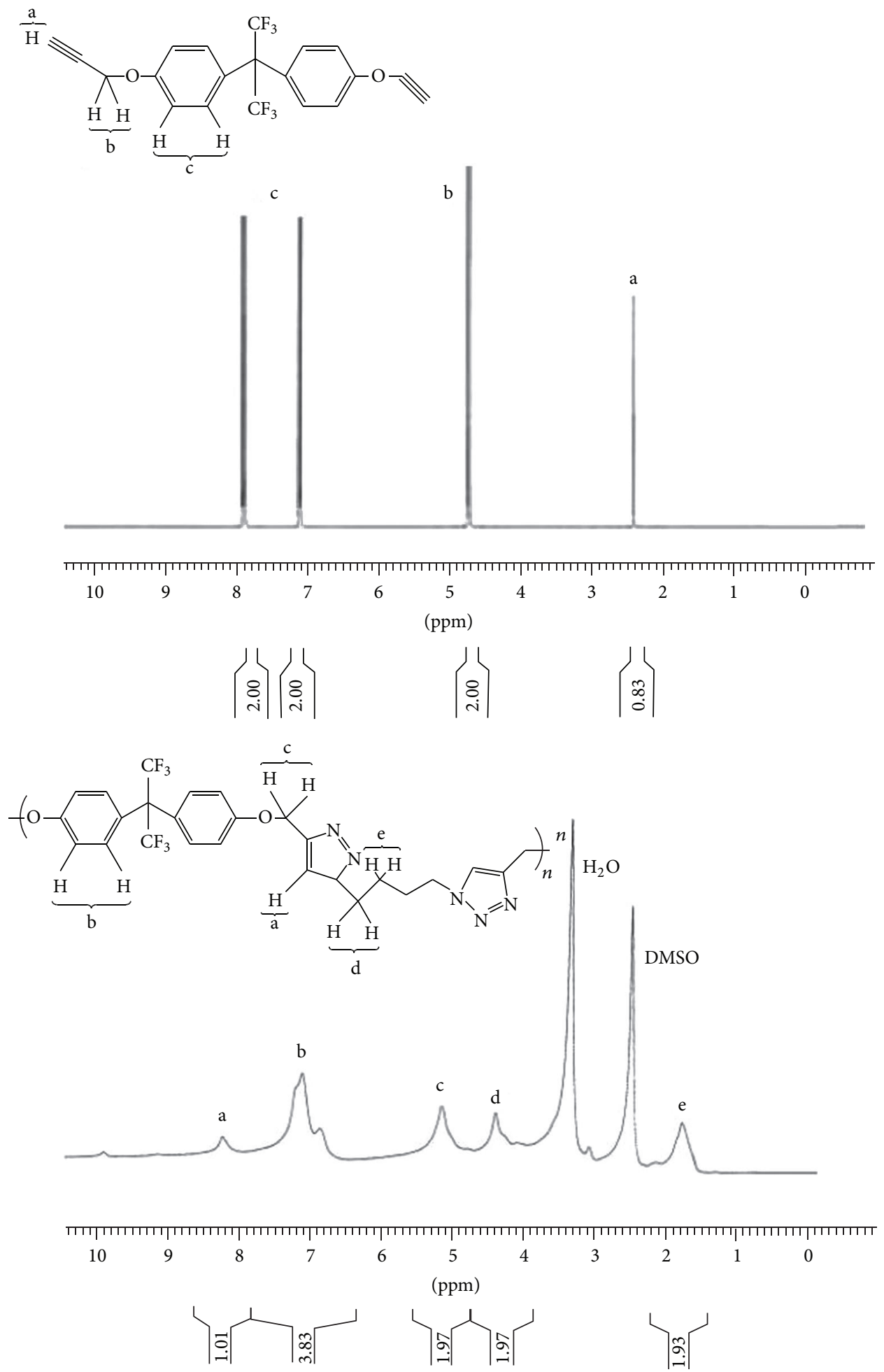

Figure 2: $400 \mathrm{MHz}^{1} \mathrm{H}$ NMR of $\mathbf{1 d}$ in $\mathrm{CDCl}_{3}$ and $\mathbf{P 2 d}$ in DMSO-d6.

P2c: $89 \%$ yield. IR $\left(\mathrm{KBr}, \mathrm{cm}^{-1}\right): 3155,3051,2958,1644$, $1588,1501,1453,1423,1289,1242,1156,988 .{ }^{1} \mathrm{H}$ NMR (DMSOd6, $400 \mathrm{MHz}, \mathrm{ppm}) \delta: 8.08$ (s, 2H, $\mathrm{CH}$ of triazole ring), 7.63 (br, $4 \mathrm{H}$, phenyl), 7.01 (br, $4 \mathrm{H}$, phenyl), 5.31 (br, $4 \mathrm{H}, \mathrm{CH}_{2}-\mathrm{O}$ ), 4.19 (br, $4 \mathrm{H}, \mathrm{CH}_{2}-\mathrm{N}$ ), 1.65 (br, $4 \mathrm{H}, \mathrm{CH}_{2}-\mathrm{CH}_{2}$ ). Anal. Calc. for $\left(\mathrm{C}_{23} \mathrm{H}_{22} \mathrm{~N}_{6} \mathrm{O}_{3}\right)_{n} \mathrm{C}$ 64.18, $\mathrm{H}$ 5.11, N 19.53. Found: C 65.11, $\mathrm{H}$ 5.61, N 19.27\%.

P2d: $85 \%$ yield. IR $\left(\mathrm{KBr}, \mathrm{cm}^{-1}\right)$ : 3129, 3055, 2978, 1624, $1505,1451,1407,1239,1159,1045,980,827 .{ }^{1} \mathrm{H}$ NMR (DMSO$\mathrm{d} 6,400 \mathrm{MHz}, \mathrm{ppm}) \delta: 8.23$ (s, $2 \mathrm{H}, \mathrm{CH}$ of triazole ring), 7.12 
(br, $4 \mathrm{H}$, phenyl), 6.87 (br, $4 \mathrm{H}$, phenyl), $5.15\left(\mathrm{br}, 4 \mathrm{H}, \mathrm{CH}_{2}-\right.$ O), 4.39 (br, $\left.4 \mathrm{H}, \mathrm{CH}_{2}-\mathrm{N}\right), 1.78$ (br, $4 \mathrm{H}, \mathrm{CH}_{2}-\mathrm{CH}_{2}$ ). Anal. Calc. for $\left(\mathrm{C}_{25} \mathrm{H}_{22} \mathrm{~N}_{6} \mathrm{O}_{2} \mathrm{~F}_{6}\right)_{n} \mathrm{C}$ 54.34, H 3.98, $\mathrm{N}$ 15.21. Found: C 55.69, H 4.09, N 15.61\%.

\section{Results and Discussion}

3.1. Synthesis and Characterization of Polymers. Since triazole ring is chemically inert toward oxidation, reduction, and hydrolysis conditions and has an intermediate polarity [21], incorporation of such stable structural unit in polyethers can enhance their thermophysical properties. Traditionally, 1,2,3triazoles were prepared from click reaction of azides and alkynes under $\mathrm{Cu}(\mathrm{I})$ catalysis which has been comprehensively reviewed [22]. However, low molecular weight organic azides may be unstable and should be handled with caution. Azides with a $\mathrm{C} / \mathrm{N}$ ratio greater than one and no more than 3 can be synthesized and isolated but should be stored below room temperature at no more than $1 \mathrm{M}$ concentration. Organic azides with $\mathrm{C} / \mathrm{N}<1$ should never be isolated and practically they were used without further purification [19]. Therefore, to avoid the use of azides, the polymers containing triazole unites, poly(triazole ether)s (P1a-d and P2a-d), were obtained from direct click reaction of corresponding dibromideswith bisethynyl compounds la-d in the presence of sodium azide (Scheme 2). The reactions were carried out in a $10: 2$ solvent ratio of DMF: $\mathrm{H}_{2} \mathrm{O}$ and using $20 \mathrm{~mol} \%$ $\mathrm{CuCl}$ with $\mathrm{NEt}_{3}$ as base and stabilizing agent $[23,24]$ at room temperature. It is found that the reaction in dry DMF and/or in the absence of $\mathrm{NEt}_{3}$ gives polymers in low yield. It can be seen from the infrared spectra of P1a-d and P2a-d the strong absorption peaks about 3,300 and $2,100 \mathrm{~cm}^{-1}$ assigned to stretching vibrations of $\mathrm{C} \equiv \mathrm{C}-\mathrm{H}$ and $-\mathrm{C} \equiv \mathrm{C}$, respectively, disappeared, while new strong absorption peaks at 3042$3085 \mathrm{~cm}^{-1}$ corresponding to stretching vibration of $\mathrm{C}=\mathrm{C}-\mathrm{H}$ of the 1,2,3-triazole moiety appeared (Figure 1). Representative ${ }^{1} \mathrm{H}$ NMR spectrum of monomer $\mathbf{1 d}$ and its aliphatic polymer P2d is shown in Figure 2. It is clear that the 1,2,3triazole rings of the polymer were characterized by signals near $8.2 \mathrm{ppm}$ corresponding to triazole protons. As seen in ${ }^{1} \mathrm{H}$ NMR spectrum of the polymer P2d, it confirmed that the resulting polymers contain triazole units corresponding to IR analysis. These data indicate that direct polymerization between dibromide with bisethynyl compounds la-d in the presence of sodium azide via the click reaction was successful. In comparison with previous works for synthesis of these types of polymers [25], our method is novel, convenient, and in best agreement with click chemistry requirements (benign solvents, room temperature, simple isolation,...) and the most important feature of this method is the one pot synthesis that prevents from further purification and use of dangerous diazide compounds.

3.2. Consideration of Molecular Weights and Distributions of Polymers. The corresponding data of GPC analysis in DMF for polymers were showed in Table 1 . The results show that the polymerization via click chemistry produced polymers with adequately high molecular weights and narrow distributions.

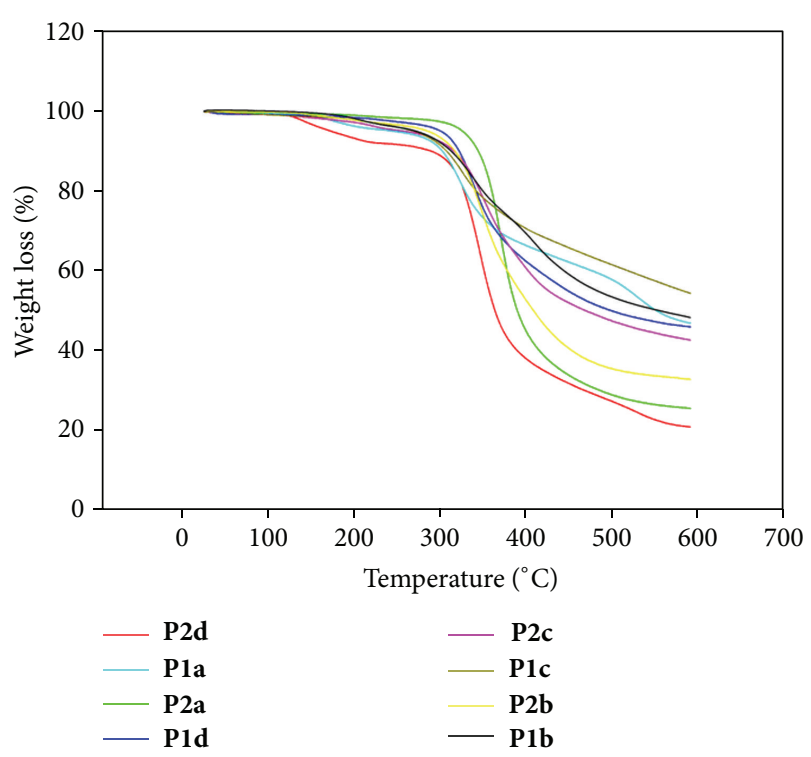

FIgURE 3: Thermogravimetric analysis under $\mathrm{N}_{2}$ atmosphere and heating rate of $10^{\circ} \mathrm{C} / \mathrm{min}$.

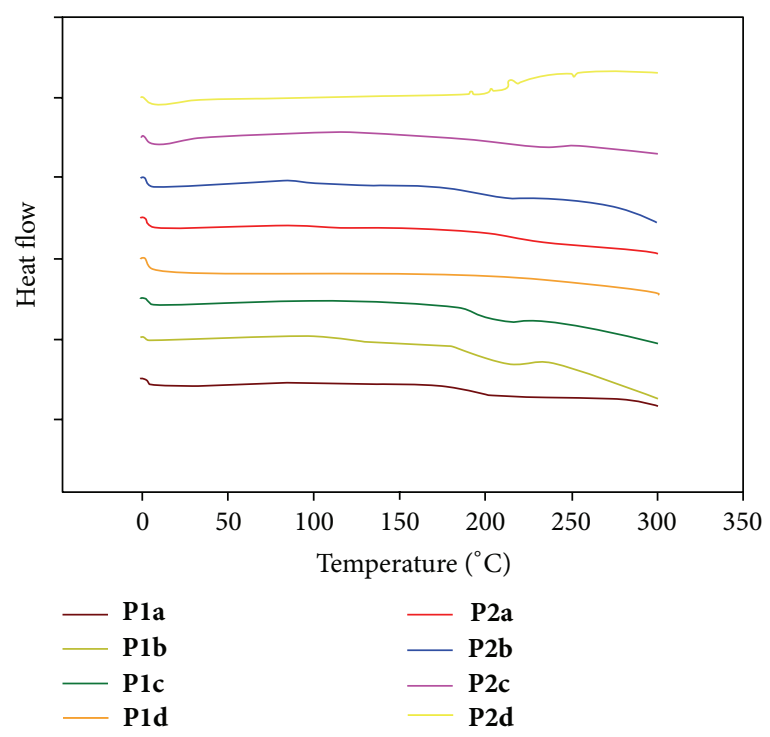

FIgURE 4: Differential scanning calorimetric under $\mathrm{N}_{2}$ gas with heating rate of $10^{\circ} \mathrm{C} / \mathrm{min}$.

The number average molecular weights of them are between 17,300 and 24,800 and the distributions range is from 1.09 to 1.68. All polydispersities of polymers are less than 1.68 which is standard for polymerization reaction [26]. According to the high molecular weight and narrow distribution, it is found that the click chemistry is an effective route for polymerization.

3.3. Solubility Behavior of Polymers. The solubility of polymers was quantitatively determined in common organic solvents by dissolving $5.0 \mathrm{mg}$ of solid polymers in $1.0 \mathrm{~mL}$ of solvents. In the solubility experiments, it was found that these polymers were completely insoluble in $\mathrm{MeOH}$, THF, EtOAc, 

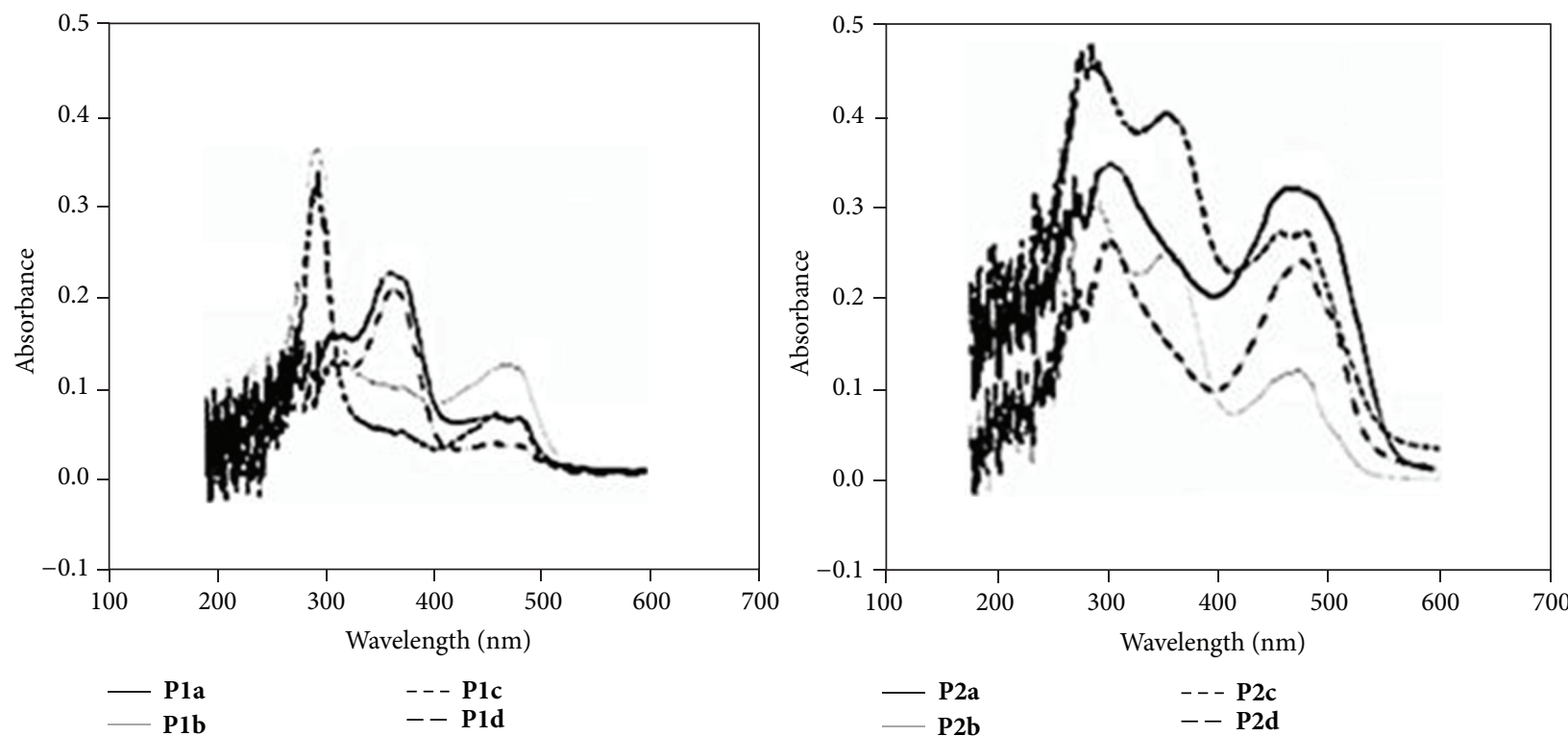

Figure 5: UV-vis absorption spectra of P1a-d and P2a-d were recorded using a dilute polymer solution (0.20 g/dL) in DMSO.

TABLE 1: Molecular weights and distributions of polymers.

\begin{tabular}{lcccc}
\hline Polymers & $M_{n}{ }^{\mathrm{a}}$ & $M_{w}{ }^{\mathrm{a}}$ & $\left(M_{w} / M_{n}\right)^{\mathrm{a}}$ & $\eta_{\text {inh }}(\mathrm{dl} / \mathrm{g})$ \\
\hline P1a & 23,100 & 29,800 & 1.29 & 0.62 \\
P1b & 21,000 & 32,200 & 1.53 & 0.58 \\
P1c & 21,300 & 32,800 & 1.54 & 0.55 \\
P1d & 24,800 & 27,000 & 1.09 & 0.63 \\
P2a & 19,100 & 30,900 & 1.62 & 0.45 \\
P2b & 17,300 & 29,100 & 1.68 & 0.42 \\
P2c & 20,500 & 27,500 & 1.34 & 0.49 \\
P2d & 22,400 & 27,300 & 1.22 & 0.58 \\
\hline
\end{tabular}

${ }^{\mathrm{a}} \mathrm{GPC}$ in DMF versus polystyrene in flow rate of $1.0 \mathrm{~mL} / \mathrm{min}$ at $35^{\circ} \mathrm{C}$.

TABLE 2: Thermal properties of polymers.

\begin{tabular}{lccccc}
\hline Polymers & $T_{5}\left({ }^{\circ} \mathrm{C}\right)$ & $T_{10}\left({ }^{\circ} \mathrm{C}\right)$ & $T_{50}\left({ }^{\circ} \mathrm{C}\right)$ & Char yield $(\%)$ & $T_{g}\left({ }^{\circ} \mathrm{C}\right)$ \\
\hline P1a & 249.6 & 321.4 & 499.5 & 46 & 210 \\
P1b & 274.2 & 313.8 & 556.7 & 48.3 & 260 \\
P1c & 271.3 & 309 & - & 54.46 & 220 \\
P1d & 302.2 & 310.9 & 558.8 & 44.3 & 212.5 \\
P2a & 327.1 & 345.6 & 390.9 & 25.6 & 191.7 \\
P2b & 287.4 & 319.1 & 410.2 & 32.9 & 196.7 \\
P2c & 261.7 & 316.05 & 469.64 & 42.7 & 208.3 \\
P2d & 175.2 & 297.5 & 370.8 & 18.7 & 196.8 \\
\hline
\end{tabular}

and toluene at room and high temperatures. But polymers showed low solubility in DMSO, DMF, and NMP at room temperature and good solubility at higher temperatures.

3.4. Thermal Properties of Polymers. Thermal stabilities of P1a-d and P2a-d were evaluated by means of thermogravimetric analysis (TGA) and differential scanning calorimetric (DSC). The resulting data are summarized in Table 2. The resulting polymers exhibited high resistance to thermal decomposition up to $558^{\circ} \mathrm{C}$ under nitrogen gas and decompose gradually above that temperature which is probably attributed to chain scission of ether linkage. It was seen from Figure 3 that rates of weight loss of aliphatic polymers were greater than aromatic polymers due to the decomposition of methylene groups. The glass transition temperature $\left(T_{q}\right)$ of polymers, determined by DSC, ranged between 191.7 and $260^{\circ} \mathrm{C}$ and increased with the increase of conformational rigidity (Table 2). As was expected, since $\mathbf{P} \mathbf{l b}$ has rigid sulfone groups in the polymer, backbone which restricts molecular rotation $T_{g}$ of $\mathbf{P} \mathbf{1 b}$ is the highest. P2a was the lowest owing to higher flexibility of the methyl groups. The data reveal that $T_{g}$ decreases with the nature of the aliphatic chain spacer. Absence of crystallization temperature in DSC curves (Figure 4) also shows the amorphous nature of the polymers, which was confirmed by X-ray diffraction studies. Inherent viscosity $\left((\eta)_{\text {inh }}=\ln \eta_{\text {rel }} / c\right)$ at a concentration of $0.5 \mathrm{~g} / \mathrm{dL}$ was measured with an Ubbelohde suspended-level viscometer at $25^{\circ} \mathrm{C}$ in DMSO solution. Viscometry studies exhibited that polymers have moderate molecular weight (Table 1).

3.5. UV-Vis Properties of the Polymers. The photophysical properties of the P1a-d and P2a-d were investigated by UVvisible spectroscopy in DMSO solution. There are similar pair curves as can be seen in UV-vis diagrams (Figure 5) which exhibited strong absorption at $283 \mathrm{~nm}$ and $465 \mathrm{~nm}$ corresponding to phenyl and triazole rings of the polymer backbones, respectively. The presence of extra conjugation of $-\mathrm{SO}_{2}$ and $-\mathrm{CO}$ groups in the backbone of the polymer caused some blue shift. This effect has not be seen for the polymers bearing $-\left(\mathrm{CH}_{3}\right)_{2}-$ and $-\left(\mathrm{CF}_{3}\right)_{2}-$ spacer due to conjugation loss. Indeed, owing to the existence of different aromatic rings with different linkage between them, three characteristic absorption picks could be seen in P2b and P2c. The picks 


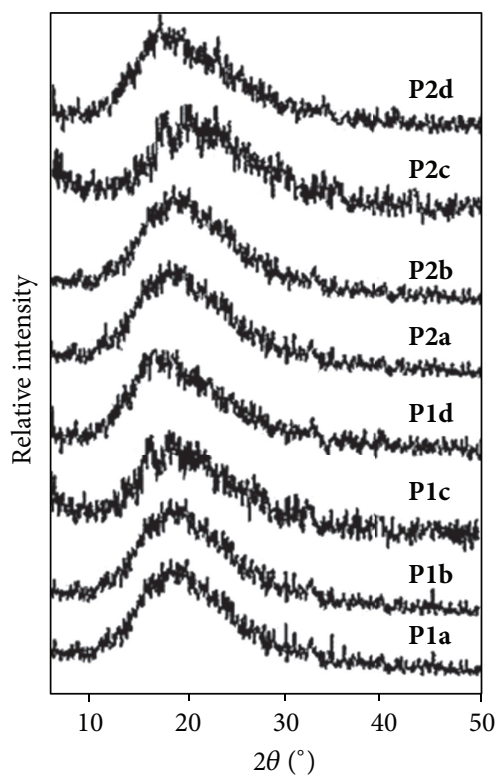

FIGURE 6: X-ray diffraction (XRD) patterns at room temperature on a powder diffractometer.

about 280 and 354 and about $480 \mathrm{~nm}$ are corresponding to arylenes and triazole rings, respectively [27, 28].

3.6. X-Ray Diffraction Studies of Polymer P1a-d and P2a$\boldsymbol{d}$. In order to further consider the crystallinity of these series of polymers, all polyether triazoles were characterized by X-ray diffractograms. The X-ray diffractogram curves of polymers were shown in Figure 6. XRD of all polymers demonstrates broad halo at about $2 \theta$ at $15-30^{\circ}$ in the wide angle region exhibiting that the polymers P1a-d and P2ad are amorphous in nature which is in agreement with the DSC analysis. This result could be explained that the etheric linkage caused the flexibility of the polymer chain which restricted the ordered arrangement of polymer chains.

\section{Conclusion}

In this work, convenient tricomponent click polymerizations of dialkynes containing ether linkages and dibromides were achieved in the presence of sodium azide to synthesize various polyethers (P1a-d and $\mathbf{P} \mathbf{2} \mathbf{a}-\mathbf{d})$. This polymerization accompanied the formation of triazoles in the polyether main chain by a $\mathrm{Cu}(\mathrm{I})$ catalyst in excellent yields. It is found that triazole ring formation in the polyether main chain leads to improved thermal properties. This work is a report of convenient synthesis of polymers that the triazoles rings inserted into backbone of the polymers under mild conditions. These fundamental results provide a new guideline to synthesize frontier polyether-based materials.

\section{Acknowledgment}

The financial supports by Research Council of Mazandaran University are gratefully acknowledged.

\section{References}

[1] R. J. Cotter, Engineering Plastics: A Handbook of Polyaryl Ethers, Gordon and Breach, Amsterdam, The Netherlands, 1995.

[2] I. S. Chung and S. Y. Kim, "Poly(arylene ether)s via nitro displacement reaction: synthesis of poly(biphenylene oxide)s containing trifluoromethyl groups from AB type monomers," Macromolecules, vol. 33, no. 26, pp. 9474-9476, 2000.

[3] C. J. Hawker and K. L. Wooley, "The convergence of synthetic organic and polymer chemistries," Science, vol. 309, no. 5738, pp. 1200-1205, 2005.

[4] S. Hecht, "Construction with macromolecules," Materials Today, vol. 8, no. 3, pp. 48-55, 2005.

[5] H. C. Kolb, M. G. Finn, and K. B. Sharpless, "Click chemistry: diverse chemical function from a few good reactions," Angewandte-Chemie International Edition, vol. 40, no. 11, pp. 20042021, 2001.

[6] R. Huisgen, S. Guenter, and M. Leander, "1.3-Dipolare cycloadditionen, XXXII. Kinetik der additionen organischer azide an CC-mehrfachbindungen," Chemische Berichte, vol. 100, no. 8, pp. 2494-2507, 1967.

[7] R. Huisgen, 1, 3-Dipolar Cycloaddition Chemistry, John Wiley \& Sons, New York, NY, USA, 1984.

[8] V. V. Rostovtsev, L. G. Green, V. V. Fokin, and K. B. Sharpless, "A stepwise huisgen cycloaddition process: copper(I)-catalyzed regioselective "ligation" of azides and terminal alkynes," Angewandte-Chemie International Edition, vol. 41, no. 14, pp. 2596-2599, 2002.

[9] C. W. Tornøe, C. Christensen, and M. Meldal, "Peptidotriazoles on solid phase: [1,2,3]-triazoles by regiospecific copper(I)-catalyzed 1,3-dipolar cycloadditions of terminal alkynes to azides," The Journal of Organic Chemistry, vol. 67, no. 9, pp. 3057-3064, 2002.

[10] A. J. Scheel, H. Komber, and B. I. Viot, "Novel hyperbranched poly([1,2,3]-triazole)s derived from $\mathrm{AB}_{2}$ monomers by a 1,3dipolar cycloaddition," Macromolecular Rapid Communications, vol. 25, no. 12, pp. 1175-1180, 2004.

[11] P. Wu, A. K. Feldman, A. K. Nugent et al., "Efficiency and fidelity in a click-chemistry route to triazole dendrimers by the copper(I)-catalyzed ligation of azides and alkynes," Angewandte-Chemie International Edition, vol. 43, no. 30, pp. 39283932, 2004.

[12] D. J. V. C. van Steenis, O. R. P. David, G. P. F. van Strijdonck, J. H. Van Maarseveen, and J. N. H. Reek, "Click-chemistry as an efficient synthetic tool for the preparation of novel conjugated polymers," Chemical Communications, no. 34, pp. 4333-4335, 2005.

[13] B. Helms, J. L. Mynar, C. J. Hawker, and J. M. J. Fréchet, "Dendronized linear polymers via "click chemistry'," Journal of the American Chemical Society, vol. 126, no. 46, pp. 15020-15021, 2004.

[14] B. Parrish, R. B. Breitenkamp, and T. Emrick, "PEG- and peptide-grafted aliphatic polyesters by click chemistry," Journal of the American Chemical Society, vol. 127, no. 20, pp. 7404-7410, 2005.

[15] J. B. Carroll, B. J. Jordan, H. Xu et al., "Model systems for flavoenzyme activity: site-isolated redox behavior in flavin-functionalized random polystyrene copolymers," Organic Letters, vol. 7, no. 13, pp. 2551-2554, 2005.

[16] J. A. Opsteen and J. C. M. van Hest, "Modular synthesis of block copolymers via cycloaddition of terminal azide and alkyne 
functionalized polymers," Chemical Communications, no. 1, pp. 57-59, 2005.

[17] D. D. Díaz, S. Punna, P. Holzer et al., "Click chemistry in materials synthesis. 1. Adhesive polymers from copper-catalyzed azide-alkyne cycloaddition," Journal of Polymer Science A, vol. 42, no. 17, pp. 4392-4403, 2004.

[18] D. A. Ossipov and J. Hilborn, "Poly(vinyl alcohol)-based hydrogels formed by "click chemistry'",' Macromolecules, vol. 39, no. 5, pp. 1709-1718, 2006.

[19] Y. Nagao and A. Takasu, "Click polyester: synthesis of polyesters containing triazole units in the main chain by click chemistry and improved thermal property," Macromolecular Rapid Communications, vol. 30, no. 3, pp. 199-203, 2009.

[20] R. X. Yao, L. Kong, Z. S. Yin, and F. L. Qing, "Synthesis of novel aromatic ether polymers containing perfluorocyclobutyl and triazole units via click chemistry," Journal of Fluorine Chemistry, vol. 129, no. 10, pp. 1003-1010, 2008.

[21] P. Wu and V. V. Fokin, "Catalytic dipolar cycloaddition of azides and alkynes: reactivity and applications," Aldrichimica Acta, vol. 40, no. 1, pp. 7-17, 2007.

[22] M. Meldal and C. W. Tornøe, "Cu-catalyzed azide-alkyne cycloaddition," Chemical Reviews, vol. 108, no. 8, pp. 2952-3015, 2008.

[23] G. C. Tron, T. Pirali, R. A. Billington, P. L. Canonico, G. Sorba, and A. A. Genazzani, "Click chemistry reactions in medicinal chemistry: applications of the 1,3-dipolar cycloaddition between azides and alkynes," Medicinal Research Reviews, vol. 28, no. 2, pp. 278-308, 2008.

[24] V. D. Bock, H. Hiemstra, and J. V. Maarseveen, " $\mathrm{Cu}^{\mathrm{I}}$-catalyzed alkyne-azide "click" cycloadditions from a mechanistic and synthetic perspective," European Journal of Organic Chemistry, vol. 2006, no. 1, pp. 51-68, 2006.

[25] L. Wang, J. Li, and L. Wang, "Study on synthesis of paeks containing triazole units through click reaction and their properties," Bulletin of the Korean Chemical Society, vol. 32, no. 9, pp. 3306-3310, 2011.

[26] I. B. Mansour, K. Alouani, E. Chauveau, V. Martin, F. Schiets, and R. Mercier, "Synthesis and characterisation of poly(esteramide)s from aromatic bisoxazoline precursors," European Polymer Journal, vol. 46, no. 4, pp. 814-820, 2010.

[27] C. Saravanan, S. Senthil, and P. Kannan, "Click chemistry-assisted triazole-substituted azobenzene and fulgimide units in the pendant-based copoly(decyloxymethacrylate)s for dual-mode optical switches," Journal of Polymer Science A, vol. 46, no. 23, pp. 7843-7860, 2008.

[28] B. Happ, C. Friebe, A. Winter, M. D. Hager, and U. S. Schubert, "Click chemistry meets polymerization: controlled incorporation of an easily accessible ruthenium(II) complex into a PMMA backbone via RAFT copolymerization," European Polymer Journal, vol. 45, no. 12, pp. 3433-3441, 2009. 

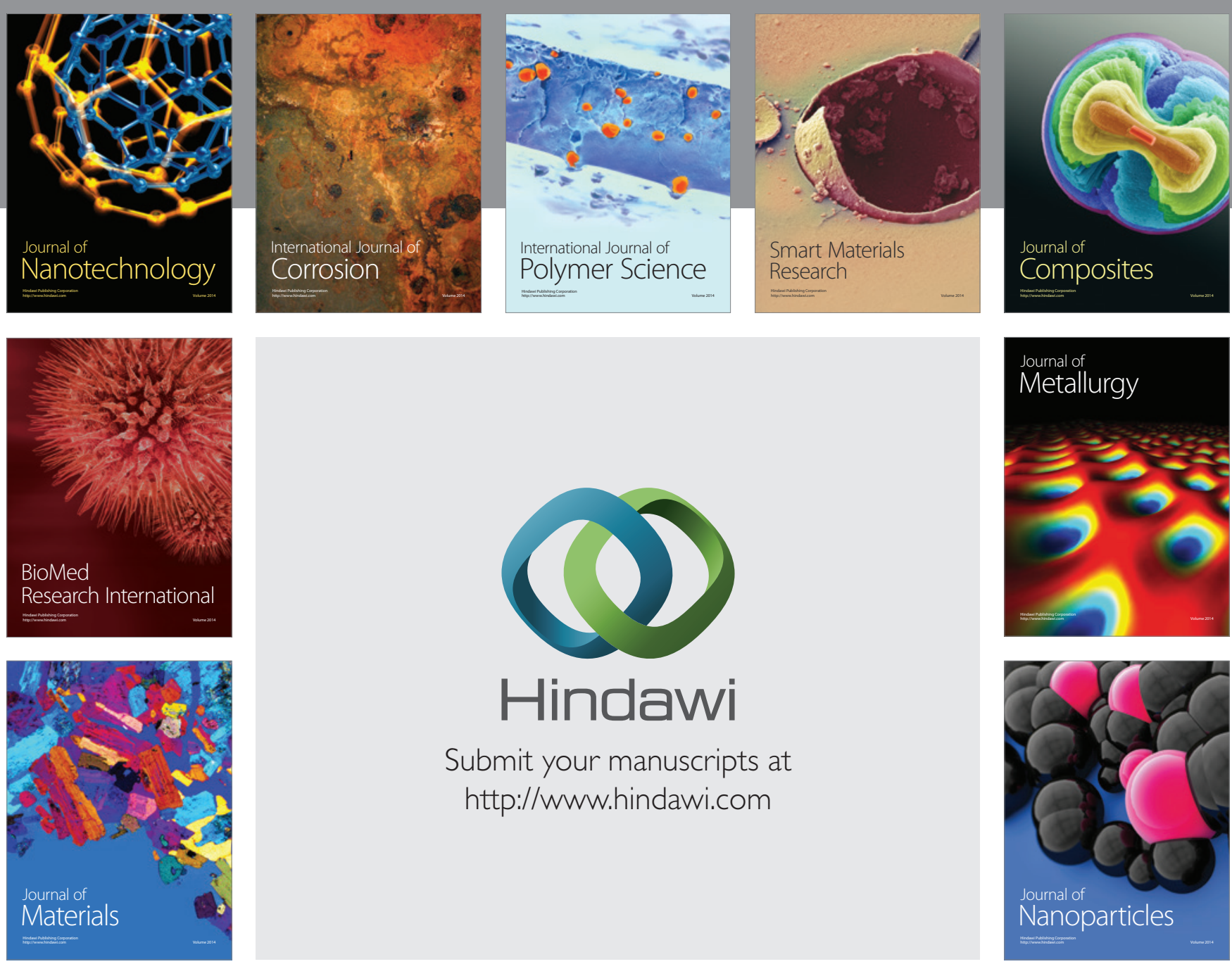

Submit your manuscripts at http://www.hindawi.com
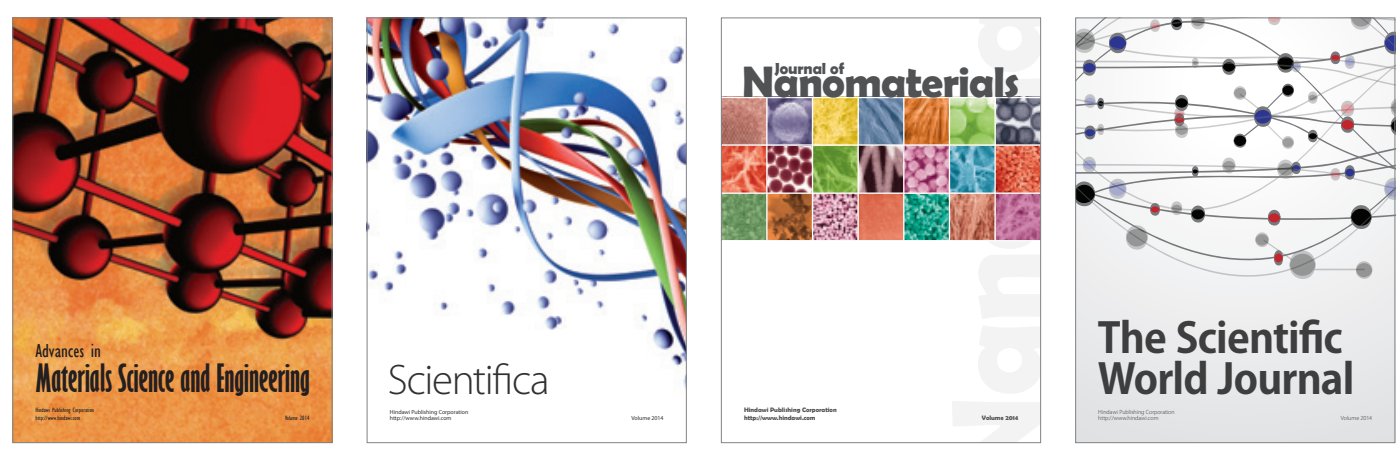

\section{The Scientific World Journal}
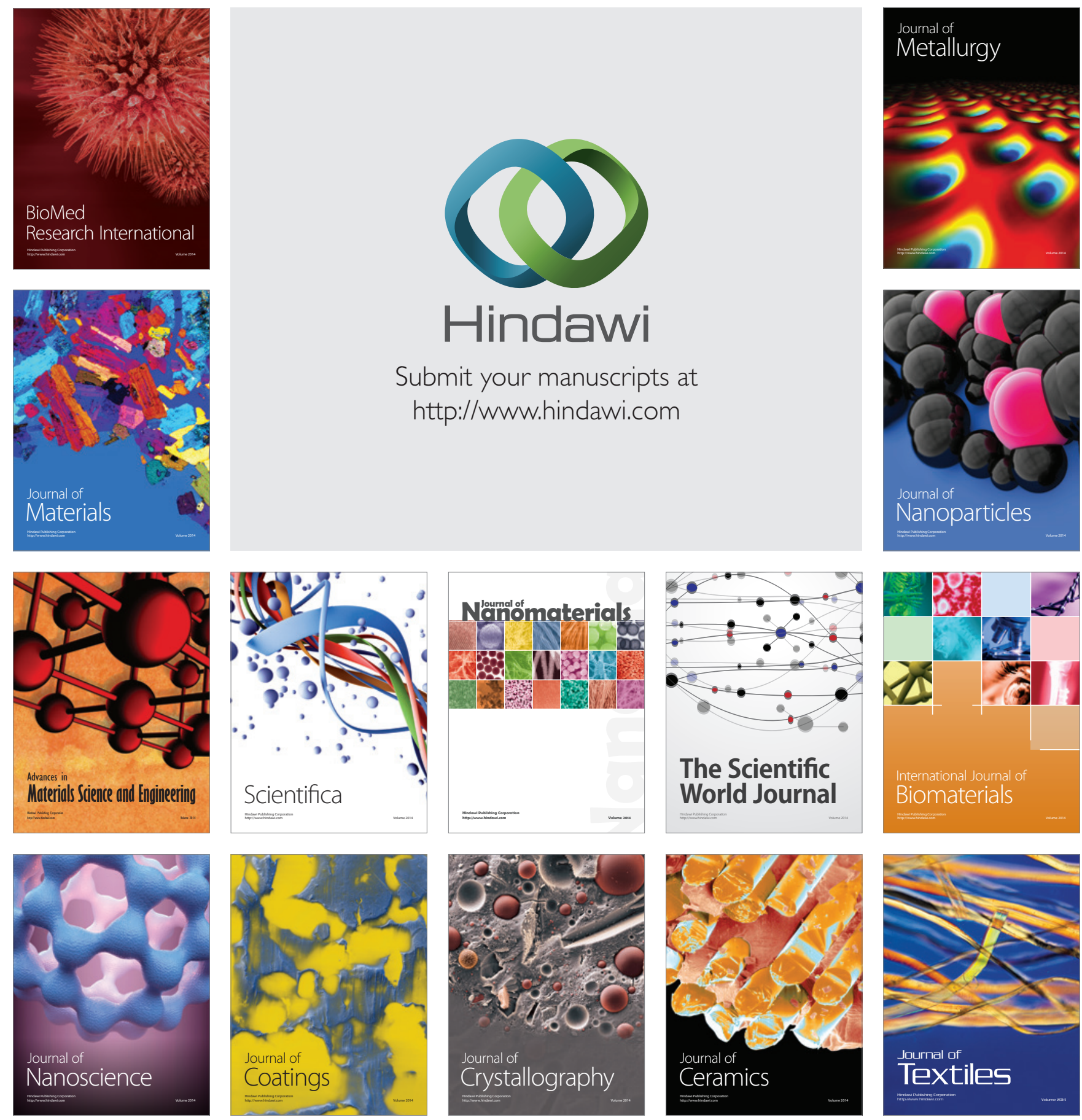